\title{
Effect of Audio-Visual Technology on Senior Secondary School Students Interest in Geometry in Makurdi Me- tropolis of Benue State
}

\author{
Anyagh PI* and Abari MT \\ Department of Science Education, Nigeria \\ *Corresponding author: Anyagh PI, Department of Science Education, Nigeria
}

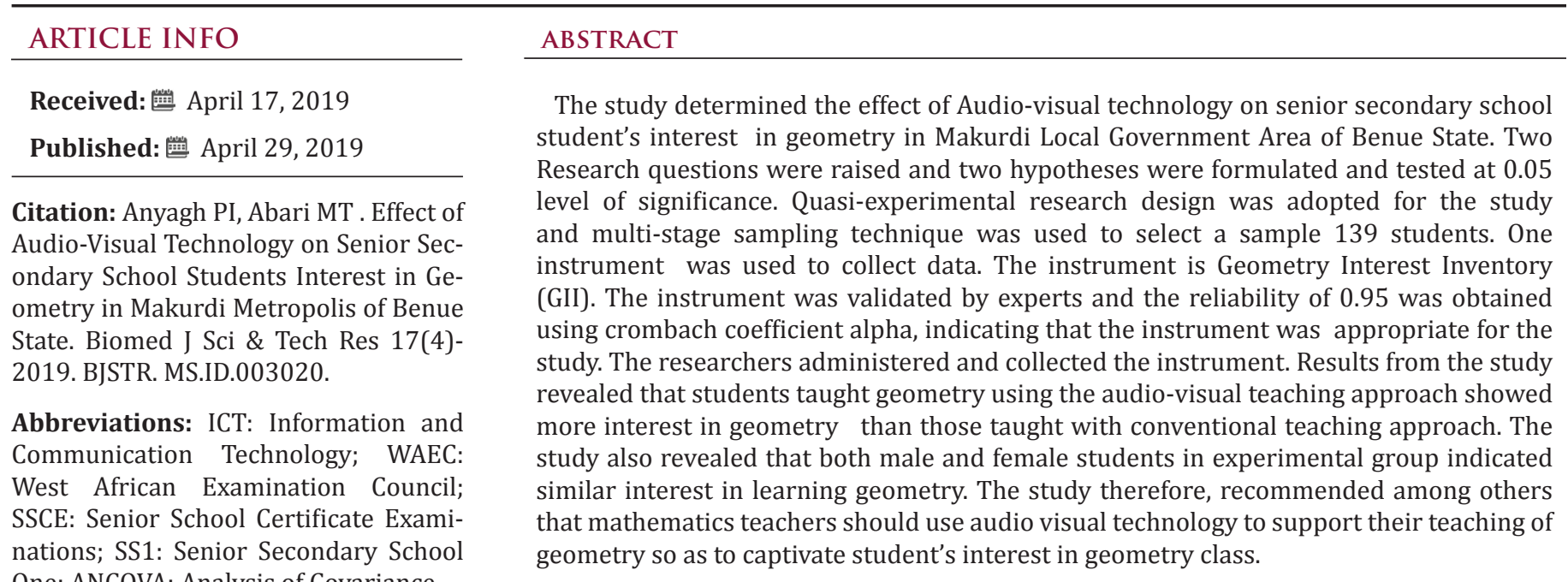
One; ANCOVA: Analysis of Covariance

Keywords: Audio Visual Technology; Interest; Geometry; Secondary School Students

\section{Introduction}

Technology can play an important role in schools to promote more meaningful and result oriented impartation and acquisition of knowledge. Some of the widely used technologies in the classrooms are computers and their associated software's, videos and projectors. According to Odili et al. [1] learning with the help of computers not only leads to the development of skills but a sense of enjoyment in the process of learning. He further stated that current software development allows teachers and students to use computers without necessarily understanding the more technical hardware components. It is therefore within the purview of mathematics educators to develop or adopt instructional strategies that will enhance the interest of students in learning Geometry in the secondary school. There is a widespread belief that technologies have an important role to play in changing and modernizing educational systems and ways of learning. When one looks at the current widespread diffusion and use of Information and Communication Technology (ICT) in modern societies, especially by the youth, it becomes clear that ICT will affect the complete learning process today and in the future. Voorst [2] stated that technology is useful in helping students view Geometry less passively as a set of procedures and more actively as reasoning, exploring, solving problems, generating new information and asking new questions. Furthermore, he claimed that technology helps students to visualize certain mathematics concepts better and that it adds a new dimension to the teaching of Geometry. The term geometry was derived from two Greek words 'geo' meaning 'earth' and 'metry' meaning 'measure'. Geometry as a concept involves visual representation of data, for example charts, solid and plane shapes. It is a meeting point between mathematics theory and mathematics as model resources. 
According to Santos [3], new technologies have challenged the routine manipulation of data using paper and pencil, since they offer more effective strategies for solving problems with greater precision. The place of technology in facilitating teaching and learning has been a major concern of researchers in recent times. Apparently, because of this concern, different researches have been carried out on effective use of different geometry software in facilitating teaching and learning in various parts of the world. It is in concert with the trend of the use of technology in the class room that Torhurst [4] observed that mathematics educators are now introducing more and various forms of multimedia presentation into their classroom activities. One of such software is Audio-visual technology which has proven through various researches to be an effective mathematics software in learning geometry as noted by Dikorich. Audio-visual is a technology that has both sound and imagery effect. Presentations using audio visual technology appeal to the sense of sight and hearing. Brunner recommended in his constructivism theory the use of visual aids in teaching and learning as they provide vicarious experiences and images that can enrich and supplement the actual experience of the students in the class room.

Perney et al. [5] noted that Geometry as a mathematics concept does not awaken great delight among secondary school students and this affect their interest in it at the higher level of their studies. Perhaps one of the reasons for the poor interest in geometry and subsequent low achievement in mathematics in secondary school could be attributed to the absence of innovative teaching. And once a student's mind is not captured in the classroom, there is little or nothing any teacher can do to improve the achievement of such a student. Though some children may be intellectually and physically capable of learning, they may never learn until their interest is stimulated. The West African Examination Council (WAEC) Chief Examiner's Report [6] after noting candidate's greater weakness in Geometry suggested that teachers should help students improve their achievement and develop their interest in Geometry by reducing the abstractness of the concepts taught in it and remove their apathy and fears of the subject. It becomes necessary to look for interventions that could be manipulated in order to improve student's interest in learning Geometry as a concept in Mathematics in the secondary schools. Significant researches have also indicated the influence of gender on interest and achievement of students in Mathematics.

Agwagah [7] had reported that female students perform significantly better than their male counterparts in Mathematics. On the contrary, Harbour-Peters [8] share the view that boys outperform girls in mathematics. Meanwhile, other research findings have argued the idea of gender disparity in interest and achievement in mathematics (Olangunju 2001). Consequently, there is no gain saying that gender disparity exists in student's interest and achievement in Geometry, but Etukudo [9] emphasized that gender disparity exist in the face of weak methods. Therefore, the search for a good instructional delivery strategy that may stimulate the interest of student's in Geometry and facilitate their overall achievement in Mathematics cannot be overemphasized. However, there is need to find out if audio-visual technology may be that instructional strategy that will help to improve the interest of student's in Geometry.

\section{Statement of the Problem}

Geometry is a mathematics concept with its roots in such diverse fields as agriculture, education, astronomy and engineering. A country like Nigeria that is aspiring to be a developed nation need to be very proficient in science and technology; thus she deserve mathematically literate people. Yet, secondary school student's low achievement in mathematics has assumed alarming proportions and has caused a lot of concern to mathematics educators, parents and successive governments for many years. The chief examiner's reports in mathematics in Senior School Certificate Examinations (SSCE) conducted by the West African Examinations Council (WAEC) and National Examination Council in the preceding years (2012-2015) underscore the consistent rate of failure of secondary school students in mathematics due to their inability to answer geometry related questions correctly. The WAEC examiner's report also reveal that a good number of student's fail to attempt the geometry related questions in the theory part of the SSCE and those that attempt it usually perform below expectation. This according to Alpizar (2007), is a trend that has been traced through various studies to deficiency in primary and secondary geometry learning. Could it be that teachers' failure to use appropriate stimulating teaching methods are responsible for student's poor knowledge and interest in geometry? The issue then is, would the use of audio-visual in teaching geometry facilitate student's interest in mathematics?

\section{Purpose of the Study}

The main purpose of this study was to find out if the adoption of audio-visual in teaching would help in improving student's interest in geometry. Specifically, the study sought to:

a) Determine the mean interest rating in geometry of senior secondary school students in the experimental and control groups.

b) Determine the mean interest rating in geometry of male and female senior secondary school students in the experimental group.

\section{Research Questions}

The following research questions were raised to guide the study:

a) What is the mean interest rating in geometry of senior secondary school students in the experimental and control groups?

b) What is the mean interest rating in geometry of male and female senior secondary school students in the experimental group? 


\section{Research Hypotheses}

The following hypotheses were formulated for the study and are tested at 0.05 level of significance:

a) There is no significance difference in the mean interest rating in geometry of students in the experimental and control groups.

b) There is no significant difference in the mean interest rating in geometry of male and female students in the experimental group.

\section{Methodology}

The design adopted for this study was quasi- experimental design of non-equivalent group. This design was selected because it is not possible for the study to have full control of the scheduling of experimental condition and to have a complete randomization of subjects as this would affect the normal classroom organization of the selected schools. Intact classes were assigned at random to the experimental and control groups using lottery method to determine which is to be the experimental and control group. Specifically, the design of the study was Pre-test-Post test control group design, where the experimental group was taught using Audio-visual technology while the control group was taught using the conventional method. The population of the study was all the 2,412 Senior Secondary School one (SS1) students in Makurdi Local Government Area of Benue State (BSTSB 2015). A sample of 139 students was selected using multistage sampling technique. Multistage sampling technique was used for the study because different sampling techniques were applied at different stages of the research. The sampling techniques used at different stages were

i. Purposive sampling techniques.

ii. Simple random sampling technique. Purposive sampling technique was used to select the schools. The schools selected met the following conditions:
a) Co-educational.
b) Had computer laboratory.
c) And were government schools.

Simple random sampling was used in selecting the classes where there are more than two streams assigned to the experimental and control groups. One instrument was used to collect data. The instrument was Geometry Interest Inventory (GII). The instrument was validated by experts. The reliability of the GII was calculated using Crombach alpha coefficient and the value obtained was 0.95, indicating that the instrument is appropriate for the study. Data collated was analyzed using descriptive statistics of mean and standard deviation to answer the research questions asked while the hypotheses were tested at 0.05 significance level using the analysis of covariance (ANCOVA).

\section{Results}

Result of this study was presented according to the research questions followed with related hypotheses.

\section{Research Question 1}

What is the mean interest rating in geometry of senior secondary school students in the Audio-visual method and conventional method group? Results in Table 1 shows that the mean interest scores of students taught geometry with Audio-visual technology method was 52.01 with a standard deviation of 5.46, while those taught geometry with Conventional approach was 38.27 with a standard deviation of 2.85 . The mean gain of the students taught geometry with Audio-visual technology was 20.31 while that of the students taught geometry with conventional approach was 8.68. Therefore the mean interest rating of the students taught geometry with the Audio-visual technology method is higher than those taught geometry with the conventional method. This implies that the students taught geometry using the Audio-visual technology method showed higher interest in learning geometry than the students in the conventional method group. To show if the mean interest rating in geometry of students between the experimental and control group is significant, hypothesis 1 was tested at $=0.05$.

Table 1: Mean Rating and Standard Deviation of Students in Audio-visual Method and Conventional Method Groups.

\begin{tabular}{|c|c|c|c|}
\hline Teaching Method & Type of Test & Mean & Standard Deviation (SD) \\
\hline \multirow{3}{*}{ Audio-visual } & Pre GII & 31.70 & 2.71 \\
& Post GII & 52.01 & 5.46 \\
& Mean Gain & 20.31 & \\
\hline \multirow{2}{*}{ Conventional } & Pre GII & 29.59 & 4.23 \\
& Post GII & 38.27 & 2.85 \\
& Mean Gain & 8.68 & \\
\hline
\end{tabular}

\section{Hypothesis 1}

There is no significance difference in the mean interest rating in geometry of students in the Audio-visual technology method and conventional method groups. In Table 2 , the above result shows that the covariance is not significantly related to the dependent variable thus a sig value of 0.015 .However, the significant value of the post interest in the two methods is 0.000 and the value is less than the level of significance of 0.05 . Thus, null hypothesis is rejected. It therefore means that Audio-visual technology method aroused more interest in the students to learn geometry than conventional method. 
Table 2: ANCOVA result on subject's post interest rating in GII.

\begin{tabular}{|c|c|c|c|c|c|c|}
\hline Tests of Between Subjects Effects Source & Type III Sum of Squares & Df & Mean Square & F & Sig. & Partial Eta Squared \\
\hline Corrected Model & $56871.755 \mathrm{a}$ & 2 & 18957.252 & 1386.218 & 0 & 0.946 \\
\hline Intercept & 442.113 & 1 & 442.113 & 32.329 & 0 & 0.12 \\
\hline Method & 198.472 & 1 & 198.472 & 14.513 & 0 & 0.057 \\
\hline preGI & 110.91 & 1 & 110.91 & 8.11 & 0.015 & 0.033 \\
\hline Error & 6894.774 & 136 & 50.7 & & & \\
\hline Total & 378892 & 139 & & & \\
\hline Corrected Total & 60126.529 & 138 & & \\
\hline
\end{tabular}

Note: Test of between subject's effects.

\section{Research Question 2}

What is the mean interest rating in geometry of male and female senior secondary school student in the Audio-visual technology method group? In Table 2 , the above result shows that the covariance is not significantly related to the dependent variable thus a sig value of 0.015 . However, the significant value of the post interest in the two methods is 0.000 and the value is less than the level of significance of 0.05 . Thus, null hypothesis is rejected. It therefore means that Audio-visual technology method aroused more interest in the students to learn geometry than conventional method.

\section{Research Question 2}

What is the mean interest rating in geometry of male and female senior secondary school student in the Audio-visual technology method group? From (Table 3), the result shows that the covariance (PreGII) is not the same as the dependent variable thus a significant value of 0.397 .The significance value of post geometry interest inventory of male and female students in geometry within the groups is 0.263 . Hence 0.263 is greater than 0.05 , the null hypothesis is not rejected. This result shows that within the groups there is no significance difference between the male and female student's interest in geometry. This implies that both the male and female students in experimental group showed a similar level of interest in geometry.

Table 3: Result of GII for Male and Female Student in Experimental Group.

\begin{tabular}{|c|c|c|c|c|c|}
\hline \multirow{2}{*}{} & \multicolumn{2}{|c|}{ Pre GII } & \multicolumn{2}{c|}{ Post GII } & \multirow{2}{*}{ Mean Difference } \\
\cline { 2 - 5 } & $\overline{\mathbf{x}_{-} \mathbf{1}}$ & SD1 & $\overline{\mathbf{x}_{-} \mathbf{1}}$ & $\mathbf{S D 2}$ & \\
\hline Male & 29.65 & 2.7 & 51.73 & 2.65 & 22.08 \\
\hline Female & 29.54 & 4.97 & 51.66 & 4.82 & 22.12 \\
\hline
\end{tabular}

\section{Discussion}

Results from Table 1 shows that the mean interest scores of students taught geometry with Audio-visual technology method was 52.01 with a standard deviation of 5.46, while those taught geometry with Conventional approach was 38.27 with a standard deviation of 2.85. The mean gain of the students taught geometry with Audio-visual technology was 20.31 while that of the students taught geometry with conventional approach was 8.68. Therefore, the mean interest rating of the students taught geometry with the Audio-visual technology method is higher than those taught geometry with the conventional method. This implies that the students taught geometry using the Audio-visual technology method showed higher interest in learning geometry than the students in the conventional method group. In Table 2, hypothesis 2 was tested at $=0.05$ to confirm that the mean interest rating in geometry of students between the experimental and control group is significant. The result from Table 2 shows that the significant value of the post interest in the two methods is 0.000 and the value is less than the level of significance of 0.05 . Thus, null hypothesis was rejected. It therefore means that Audio-visual technology method aroused more interest in the students to learn geometry than conventional method.

This finding is in agreement with Odili (2006) who asserted that learning with the help of computer will lead not only to the development of skills but also a sense of enjoyment in the process of learning. This finding also agree with Ahmad and Rohani(2010) who suggested that educators need to make their teaching and learning of geometry easy for students to learn and enjoy in the class. That way, the students may sustain their interest in geometry and devote more time to study it. He also said that educators need to help students to develop their confidence and ability to solve geometry problems by preparing them to do well in geometry and to use the available technology in order to have a better understanding of the subject; this could help to prepare students to compete and function in this high-tech world. Result in Table 4 shows that the mean interest rating of the male and female students in the Audio-visual technology method was 51.73 and 51.66 respectively. However the mean gain of the male and female students in geometry was 22.08 and 21.12. Therefore, the difference in the mean interest rating between the male and female students in geometry is 0.04 . Conclusively, the result implies that there is no much difference between the male and female student's mean interest rating in geometry. However, hypothesis 2 was tested to determine if the difference in the mean interest rating between male and female student's is statistically significant or 
not. However, in Table 4 hypothesis 2 was tested to determine if the difference in the mean interest rating between male and female student's is significant or not. From the table, the result shows that

Table 4: ANCOVA Result on Subjects Post Interest Rating in GII.

\begin{tabular}{|c|c|c|c|c|c|}
\hline Source & Type III Sum of Squares & df & Mean Square & $\mathbf{F}$ & Sig. \\
\hline Corrected Model & $57353.285 a$ & 3 & 19117.762 & 1633.857 & 0 \\
\hline Intercept & 429.643 & 1 & 429.643 & 36.717 & 0 \\
\hline Pre GII & 8.436 & 1 & 8.436 & 0.721 & 0.397 \\
\hline Gender & 14.755 & 1 & 14.755 & 1.261 & 0.263 \\
\hline Pre GII* gender & 31.405 & 1 & 31.405 & 2.684 & 0.103 \\
\hline Error & 6832.244 & 134 & 50.701 & & \\
\hline Total & 440160 & 139 & & & \\
\hline Corrected Total & 60126.529 & 138 & & & \\
\hline \multicolumn{6}{|c|}{ a. R Squared $=.954$ (Adjusted R Squared $=.953$ ) } \\
\hline
\end{tabular}

Hence 0.263 is greater than 0.05 , the null hypothesis is not rejected. This result shows that within the groups there is no significance difference between the male and female student's interest in geometry. This implies that both the male and female students in experimental group indicated a similar level of interest in geometry. These findings further reveal that the female can produce exactly the same scientific knowledge and interest as the males provided that sufficient rigor is undertaken in scientific enquiry. This finding are in agreement with Sinnes (2006) who opined that for gender inequality to be removed in the class room, methods that encourage the active participation of student's in the class should be employed by the teachers.

\section{Recommendations}

The following recommendations were made based on the findings of this study;

a) Mathematics Association of Nigeria and other stakeholders in mathematics education should organize conferences and workshops where mathematics teachers should be encouraged to adopt the use of audio visual technology in teaching Geometry.

b) The government at all levels should do more than they are currently doing by equipping computer laboratories in the nation's public secondary schools.

c) School administrators and mathematics teachers should encourage students to participate in the learning process by making provision for them to access the school computer facilities intermittently to practice and discover new things for themselves.

\section{References}

1. Abiam PO, Odok JK (2006) Factors in Student's achievement in different branches of secondary school Mathematics. Journal of Education and Technology 1(1): 161-168.

2. Voorst C (1999) Technology in mathematics teacher education. the significance value of post geometry interest inventory of male and female students in geometry within the groups is 0.263 .
3. Santos M (1997) Problem-Solving principles and Methods in learning Mathematics. Mexico. Group Editorial Iberoamericario.

4. Tolhurst D (1995) Hypertext, hypermedia, multimedia defined? Educ. Technol 35(2): 21-26.

5. Perney CK, Ravid CT (1990) The effects of college students use of Graphics Calculators on the learning algebraic concepts. Unpublished doctoral dissertation university of North Dakota, Dissertation Abstracts International 55(12): 377.

6. (2012-2015) West African Examination Council. Chief Examiner's Report. Lagos: WAEC, Statistics Division.

7. Agwagah UNV (1993) Instructions in mathematics reading as a factor in students' achievement and interest in word problem-solving. Unpublished doctoral thesis, University of Nigeria, Nsukka.

8. Harbor Peters VFA (2002) Generating and Sustaining Interest in Mathematics Classroom. In: Animalu, AOE, Harbor Peters VFA (Eds.), Proceedings of The Workshop for Re-training Mathematics Teachers at the University of Nigeria Secondary School $\left(9^{\text {th }}-11^{\text {th }}\right.$, December). Enugu: Snaap Press.

9. Abimbade J (1995) School quality factors and secondary school students' achievement in mathematics in south-western and northcentral Nigeria. The african symposium: an online journal of the African educational research network 11(1): 1-10.

10. Ahmad FM, Rohani AT (2010) Graphing calculator strategy in teaching and learning of Mathematics: Effects on Conceptual and Procedural Knowledge Performance and Instructional Efficiency.

11. Ali A (1996) Fundamentals of Research in Education. Awka; meks publishers (Nig).

12. Benue State Teaching Service Board (2010) Directorate of planning, research and statistics.

13. Ezike RO, Obodo GC (1991) The teaching of mathematics in schools and colleges. Eha-Amufu, Division of general studies, colleges of education, Enugu state.

14. Etukudo UE (2002) The Effect of Computer-assisted Instruction on gender and performance of Junior Secondary School Students in Mathematics. ABACUS, Journal of mathematical Association Nigeria 27(1): $1-8.9$

15. Hohenwarter M Preiner J (2007) Dynamic Mathematics with Audiovisual. The Journal of online Mathematics and its Applications 7(1): $2-12$.

16. Hohenwater M, Jones K (2007) Ways of linking geometry and Algebra; The case of audio-visual path presented at the proceeding of the 
British society for research into learning mathematics, University of Northampton, UK.

17. Imoko IB, Agwagah UNV (2006) Improving students' interest in mathematics through the concept mapping technique: A focus on gender. Journal of Research in Curriculum and Teaching 1(1): 30-38.

18. Ndiyo MA (2005) Foundation of Geometry and Computer Applications. Calabar, Wusen publishers.

19. Odili AO (2006) Mathematics in Nigeria secondary schools: A teaching perspective. Lagos, Anachuna educational books.

\section{ISSN: 2574-1241}

DOI: 10.26717/BJSTR.2019.17.003020

Anyagh PI. Biomed J Sci \& Tech Res

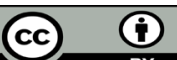

This work is licensed under Creative Commons Attribution 4.0 License

Submission Link: https://biomedres.us/submit-manuscript.php
20. Olagunju SO (2001) Sex, age and performance mathematics. ABACUS, Journal of mathematical Association of Nigeria 26(1): 8-16.

21. Royati AS, Ahmad FM, Rohani AT (2010) The Effects of Audio-visual on Mathematics Achievement: Enlightening Coordinate Geometry Learning. International Conference on Mathematics Education Research 2010 (ICMER 2010). Institute for Mathematical Research, Faculty of Educational Studies, University Putra Malaysia.

22. Sinnes AT (2005) Approaches to gender equity in science education. Two initiatives in sub-saharam African seen through a lens denied from feminist entique of science.

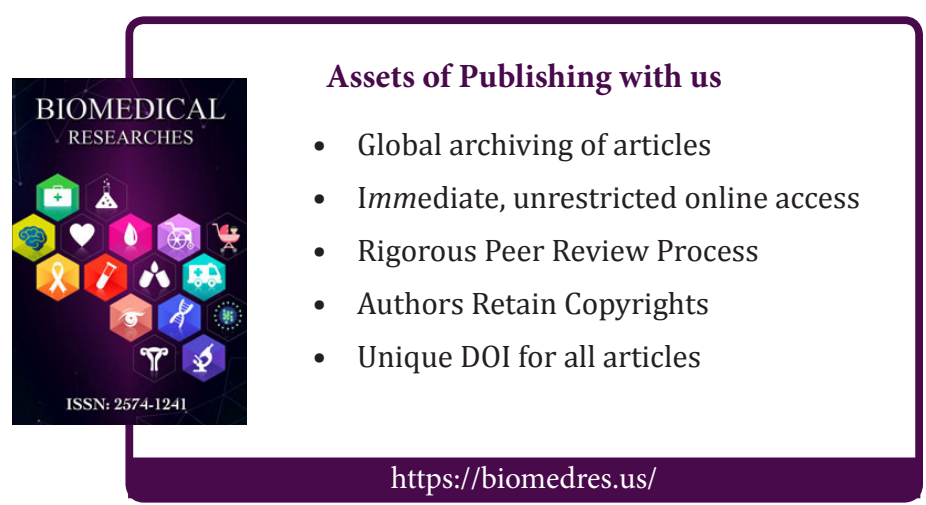

